\title{
CUÁNDO EMPIEZA LA TRANSICIÓN A LA DEMOCRACIA
}

\author{
Tomás Moulian Emparanza
}


TOMÁS MOULIAN EMPARANZA

Premio Nacional de Humanidades y Ciencias Sociales 2015. Es sociólogo titulado en la Pontificia Universidad Católica de Chile y Licenciado en Ciencias Sociales de la Universidad Católica de Lovaina. Fue director de la Escuela de Sociología de la Universidad ARCIS, donde también se desempeñó como rector. Fue subdirector de FLACSO Chile entre 1990 y 1991. Entre sus obras destacan Chile actual. Anatomia de un mito (1997), El consumo me consume (1999) y En la brecha. Derechos humanos, críticas y alternativas (2002). 


\section{CUÁNDO EMPIEZA LA TRANSICIÓN A LA DEMOCRACIA}

\section{GENERALIDADES}

Para entender la transición a la democracia en Chile es necesario previamente hablar sobre la dictadura a la cual sucedió. A continuación se indican algunas de las características más importantes del largo periodo autoritario, pues estas marcan a fuego las diferentes etapas de la transición. Cada momento de ese proceso está determinado por aquellos duros años. Sus huellas están en todas partes, marcando los diferentes momentos.

El orden de esta exposición es el siguiente. Primero se hablará brevemente de la dictadura militar, luego se analizará la primera transición.

\section{BREVES APUNTES SOBRE LA DICTADURA MILITAR}

Primero se señalan brevemente algunos rasgos esenciales de la dictadura, los que luego se definirán con mayor extensión.

La dictadura chilena fue contra revolucionaria, terrorista, caudillista y con proyecto. Fue contra revolucionaria porque pretendió anular las realizaciones de los gobiernos de Frei Montalva y Allende. Se dirigió contra la política agraria del gobierno de la llamada "revolución en libertad", en especial contra la Reforma Agraria y la sindicalización campesina. Además, desmontó la política de estatizaciones, en especial la de la banca, pero también las que afectaron al comercio y la industria. Los militares desarmaron, por consiguiente, los denominados comandos comunales y cordones industriales, aparatos a través de los cuales se realizaba la participación de los trabajadores en la gestión de las empresas durante el gobierno de Allende.

Se trató de una dictadura contraria a los dos últimos gobiernos, los cuales (como se dijo) habían introducido importantes cambios. Ello constituye un lugar común respecto del gobierno de Allende, pero casi siempre se silencia en relación al de Frei Montalva. Esta administración debe ser revalorizada. ¿Por qué? Por una razón principal: en ella se llevó a cabo un proyecto de reformismo orgánico, el cual antecede lo que viene después.

Fue también una dictadura terrorista porque operaron en ella instituciones especializadas en la represión y porque se desarrolló una política de apresamientos masivos, desapariciones de personas, lanzamientos al mar de cadáveres de las 
víctimas, torturas infligidas durante los interrogatorios o durante el encarcelamiento. Tuvo además un carácter caudillista porque a diferencia de otras dictaduras latinoamericanas como la de Brasil, donde diferentes oficiales militares se sucedían en el poder, en Chile Pinochet ocupó durante los 16 años el cargo principal.

Finalmente, fue una dictadura con proyecto, más aun, con un doble proyecto. El primero fue el cambio del sistema económico a uno de liberalismo extremo. Ese modelo fue instalado en abril de 1975 por economistas que habían realizado sus estudios de postgrado en la Universidad de Chicago. Ese modelo es afectado por la crisis económica y política de 1982, momento en el cual se intentan introducir algunos cambios durante el periodo en que Sergio Onofre Jarpa fue ministro del Interior. Más adelante, en 1986, Hernán Büchi toma la conducción de la política económica, volviendo con fuerza al neoliberalismo inicial.

El segundo elemento del proyecto fue la dictación de la Constitución de 1980, la cual define el carácter de la transición, como se verá más adelante. Esa Constitución, elaborada por un grupo de expertos a cuya cabeza estaba Enrique Ortúzar, ex ministro del presidente Jorge Alessandri, y Jaime Guzmán, el principal ideólogo de la dictadura, no solo define el periodo dictatorial, también define el futuro, ya que señala cómo debe ser lo que viene inmediatamente después del término del largo periodo represivo.

\section{LA TRANSICIÓN}

La noción de transición de este artículo no pretende justificar; no se utiliza para defender la ausencia de cambios durante un cierto periodo. Ella no se asimila a la tesis de Patricio Aylwin sobre "la medida de lo posible", la cual sí pretende defender las débiles reformas realizadas durante su mandato.

Se habla de periodo de transición para caracterizar un momento histórico donde no existe todavía en Chile una democracia representativa convencional de carácter pleno. ¿Cuándo empieza la democracia en el Chile postdictatorial, aquella que se despliega después de la derrota electoral de Pinochet? La respuesta pareciera obvia: desde el primer día del gobierno de Patricio Aylwin. Sin embargo, se trata de una respuesta equivocada.

¿Cuáles son las razones? La principal de ellas es que determinaba que el sistema político a instaurarse era una democracia con elementos autoritarios o, dicho de otro modo, una semi democracia. No hay un tránsito hacia una democracia representativa en forma sino hasta el año 2005, a fines del gobierno de Ricardo Lagos. Estos hechos a menudo se olvidan a pesar de que tienen una importancia decisiva, ya que determinan las correlaciones de fuerzas durante el proceso. 
A continuación se va a proceder a caracterizar esa primera etapa de la transición, empezando por los rasgos económico-sociales y culturales, para terminar con los elementos que definen el régimen político.

Se trata de una economía de continuidad, por tanto, con elementos de liberalismo extremo. Estos no se eliminan con la transición, solamente se corrigen y en algunos aspectos incluso se profundizan, como fue el caso de la privatización de empresas públicas durante el segundo gobierno de la transición, el de Frei Ruiz-Tagle.

Este nuevo modelo económico sustituye uno de carácter nacional popular, caracterizado por la alta participación del Estado en la gestión económica y el débil papel del mercado. Este era de larga duración, pues sus principales rasgos provenían de la década de 1920, cuando tiene lugar el primer gobierno de Arturo Alessandri Palma; más adelante estas características se fortalecen en los dos primeros gobiernos de las coaliciones de centroizquierda, los de Pedro Aguirre Cerda y Juan Antonio Ríos, también en parte del segundo gobierno de Carlos Ibáñez. Adquieren su máxima profundidad durante las administraciones de Frei Montalva y Allende. Ese sistema lo desarman los economistas de Chicago, aumentando el papel del mercado, minimizando el papel del Estado, concentrando la economía; en otras palabras, privilegiando a los grandes grupos económicos.

Esa es la situación cuando comienza la transición a partir del gobierno de Patricio Aylwin. Los economistas de la Concertación consideran que no hay condiciones para modificar profundamente el modelo, por lo que introducen correcciones, pero sin cambiar la matriz.

El comienzo de la transición también estuvo caracterizado por la mercantilización de la cultura. Esto significa que se reemplaza la cultura ideologizada de la década del ' 60 y de principios de los '70, en la cual todos los grupos políticos tenían un proyecto; por tanto, una visión de futuro. Ese modelo previo se sustituye por la pasión por el consumo y el dinero, pues estos se convierten en sentidos de vida. El modelo provee elementos facilitadores del consumismo, como son los centros comerciales, a los cuales se les llama mall, y las tarjetas de débito y de crédito. Los primeros se convierten en lugares de paseo para las familias, siendo las vitrinas los cuadros de una exposición donde los objetos se sitúan para seducir, para llamar la atención e incentivar la compra.

Estos procesos de facilitación comienzan durante la dictadura militar, pero se mantienen durante la transición. La elevación de los niveles de consumo o consumismo es, por supuesto, una condición del modelo. Por ello continúa determinando la cultura durante los diferentes momentos de la transición. Los chilenos nos hemos convertido en ciudadanos crediticios, cazados en la vorágine de las deudas generadas por la pasión por consumir. Nada de lo descrito finaliza con la dictadura, pues continúa impregnando la vida cotidiana durante la transición, no solamente de los ricos sino también de los hombres comunes y corrientes. 
El régimen político de la transición, al cual se le ha denominado semi representativo, se caracteriza por tres rasgos: a) el funcionamiento de un Senado mixto, b) la existencia de un Consejo de Seguridad Nacional y c) un régimen electoral binominal.

¿Qué es un Senado mixto? Es uno integrado por representantes electos, además de designados y/o vitalicios. En algunos países europeos existen Senados con esas características, pero en ellos la institución no tiene las mismas funciones que la Cámara de Diputados; tiene menos atribuciones. No ocurre lo mismo con el caso chileno, pues este sistema es bicameral pleno. Esto significa que el Senado tiene las mismas atribuciones que la Cámara de Diputados o incluso un poco mayores.

Por lo tanto, la modalidad del Senado mixto, en el caso chileno, afectaba gravemente la representatividad del sistema. Ello ocurría pese a que la tendencia política de los designados varió a favor del pacto de centroizquierda. Eso significó que a esa tendencia le fue menos difícil conseguir mayorías para aprobar proyectos en el Senado, pero siempre actuando en condiciones de una representatividad afectada.

El Consejo de Seguridad Nacional era, en el sistema chileno, un órgano asesor del Presidente de la República en materias de afianzamiento del orden público. Aunque su composición fue variando, durante mucho tiempo fue favorable a la derecha. Se trataba de una institución que asesoraba al mandatario en cuestiones importantes, por lo que el tenor de sus planteamientos era muy significativo.

El régimen electoral en la transición era de carácter binominal. En cada distrito de diputados o senadores se elegían dos representantes. Por efecto del funcionamiento del sistema, para elegir los dos cargos era necesario más que duplicar al adversario, cuestión que se conseguía muy pocas veces. Por ello había una tendencia al empate, pese a que la Concertación triunfaba con relativa facilidad. En muy pocas ocasiones la derecha llegó a estar por arriba del 40\% de los votos.

\section{CONCLUSIONES}

En el periodo 1989-2005 no hay en Chile todavía una democracia representativa en forma, en la cual todos los cargos fueran electos. Esta recién se despliega al final del tercer gobierno postdictatorial, el de Ricardo Lagos. Por esa razón se le ha dado al periodo referido el nombre de transición. Pero ello no quiere decir que este sea un momento histórico donde no se pueda avanzar en políticas de cambio. Significa, eso sí, que existen instituciones que tuercen la representatividad. De ellas se ha hablado al caracterizar la transición.

Conviene terminar indicando una presencia: la de Pinochet, quien recién en los primeros meses de 1998 deja de ser comandante en jefe del Ejército, pero para 
convertirse en senador vitalicio. Luego es detenido en Londres el 16 de octubre de 1998, lugar del cual regresa a Chile el 3 de marzo del 2000. Poco tiempo después se conocen fondos por 27 millones de dólares depositados en el Banco Riggs, la mayor parte de ellos mientras estaba detenido en Londres. Es importante señalar que quienes no se habían perturbado por las acusaciones de torturas y desapariciones de personas sí lo hicieran a propósito de los fondos descubiertos. 